\title{
A importância do emprego de um jogo de cartas para a revisão da nomenclatura de ácidos e bases
}

Edemar Benedetti Filho edemar@ufscar.br 0000-0002-1408-671X Universidade Federal de São Carlos, Sorocaba, São Paulo, Brasil.

\section{Alexandre Donizeti Matins} Cavagis

cavagis@ufscar.br

0000-0001-7264-900x

Universidade Federal de São Carlos, Sorocaba, São Paulo, Brasil.

Rebeca de Mello Cesar rebecaacesar@gmail.com 0000-0001-9988-9433 Universidade Federal de São Carlos, Universidade Federal de Sao

Luzia Pires dos Santos Benedetti luziabenedetti@yahoo.com.br 0000-0002-0973-7872

Universidade Federal de São Carlos, Sorocaba, São Paulo, Brasil.

\begin{abstract}
RESUMO
As atividades lúdicas têm sido objeto de estudo em diversos artigos na literatura relacionada ao Ensino de Química. O presente trabalho está inserido nesse contexto, com a elaboração e aplicação de um material pedagógico lúdico, visando a rever conceitos de Química Inorgânica, mais precisamente envolvendo aplicações, nomenclatura e conceitos referentes a ácidos e bases de Arrhenius. Para isso, foi criado um jogo de cartas, denominado "trinca química", formado por um conjunto de 52 cartas, para ser aplicado em sala de aula, em uma atividade lúdica para alunos do Ensino Médio de uma escola Estadual. A aceitação dessa metodologia alternativa pelos alunos foi bastante significativa, tendo sido constatada a importância e contribuição do jogo para o estímulo à aprendizagem, bem como para revisão e consolidação de conceitos abordados em sala de aula. 0 jogo também permitiu identificar possíveis problemas na aprendizagem dos alunos e indicar alternativas para superá-los. Além disso, a proposta foi bem aceita pela professora de Química, que relatou ter havido uma melhora significativa na relação com os alunos após a aplicação da atividade lúdica em sala de aula.
\end{abstract}

PALAVRAS-CHAVE: Atividades lúdicas. Ensino de química. Jogos. 


\section{INTRODUÇÃO}

Nas últimas décadas, temos convivido com um avanço descomunal da tecnologia e, enquanto sociedade, nos adaptamos a essas transformações que, rapidamente, têm redesenhado a forma como vivemos e enxergamos o mundo. Tais avanços vêm contribuindo sobremaneira para com o desenvolvimento de diversos campos do conhecimento, incluindo as Ciências. A comunicação teve um salto gigantesco com as novas tecnologias e, atualmente, boa parte das relações interpessoais se dá por meio de aparelhos eletrônicos (smartphones, computadores etc.). Portanto, nos dias atuais, é praticamente impossível imaginar uma sociedade que dispense o uso de tais recursos tecnológicos. Como facilitador na comunicação, não só regional ou local, mas também em nível global, a tecnologia tornou-se indispensável na vida das pessoas, permitindo-nos acessar informações em qualquer lugar e a qualquer hora (GARCEZ, 2014).

Contudo, analisando essa nova perspectiva de mundo, Garcez (2014) nos traz a reflexão de que os princípios da educação básica no Brasil não evoluíram para interagir com as novas tecnologias disponíveis: nosso processo educacional ainda se baseia nos mesmos paradigmas de séculos atrás. Nessa perspectiva, observa-se um grande entrave no processo de ensino e aprendizagem nos dias atuais, sendo que as novas tecnologias, que poderiam ser um forte aliado dos professores, na prática têm contribuído para desviar a atenção dos estudantes daquilo que o professor pretende ensinar, geralmente da mesma forma tradicional que ele próprio aprendeu.

Hoje em dia, a maioria dos alunos tem acesso à informação, por meio de smartphones constantemente conectados à internet, compartilhando diversos assuntos que lhes despertam interesse e de maneira prazerosa. Entretanto, os conteúdos pedagógicos são abordados nas salas de aula normalmente por meio de metodologias tradicionais, que negligenciam o grande potencial das metodologias alternativas e valorizam excessivamente o quadro negro e a transmissão unilateral de peças mnemônicas do conhecimento, caminhando justamente na contramão de uma aprendizagem mais dinâmica e interativa, tornando o aprendizado pouco atrativo à maioria dos estudantes e gerando um desestímulo coletivo em sala de aula.

Observa-se, na prática, que a Química quase sempre é ministrada focando a memorização de leis, fórmulas e cálculos matemáticos. Este processo educacional é bastante maçante aos alunos que, via de regra, apresentam muita dificuldade em estabelecer relações entre os conteúdos pedagógicos e seu cotidiano. Consequentemente, a disciplina torna-se desinteressante, fazendo com que os alunos a julguem levianamente como "difícil", além do que, a falta de correlação com o dia-a-dia faz com que os estudantes questionem a efetiva importância de se aprender Química, uma vez que, aparentemente, ela é totalmente descontextualizada de suas vidas (SANTANA, 2008).

Com as novidades tecnológicas disponíveis na atualidade e, considerando em grande parte o insucesso do ensino tradicional em sala de aula, faz-se necessário o uso de alternativas metodológicas, que proporcionem aos alunos novas vivências, aumentando o interesse e a motivação para o aprender (GARCEZ, 2014).

Na resolução CEB no 3, de 26 de junho de 1998, que institui as Diretrizes Curriculares Nacionais para o Ensino Médio, a fim de cumprir as finalidades 
previstas na LDB, dispõe o Artigo $5^{\circ}$ inciso III, que trata da organização dos currículos:

Adotar metodologias de ensino diversificadas, que estimulem a reconstrução do conhecimento e mobilizem o raciocínio, a experimentação, a solução de problemas e outras competências cognitivas superiores (BRASIL, 1998).

Essas novas estratégias são importantes para auxiliar no processo de aprendizagem, como por exemplo, no uso de experimentação, simulação e modelagem (GIORDAN, 1999), em que se parte de uma problemática, induzindo os alunos ao levantamento de hipóteses e remetendo-os a observações cuidadosas, coleta de dados, registros e discussões que lhes permitam chegar a conclusões seguindo uma lógica científica. Numa tentativa de refinar as explicações teóricas, o uso da contextualização e da interdisciplinaridade proposto por Sá et al. (2008), proporciona um vínculo significativo entre o conhecimento e a realidade local, por relacioná-la com um contexto mais amplo. Além disso, há diversas possibilidades de recursos pedagógicos alternativos, tais como: jornais, revistas, blogs para divulgação científica etc.

Uma estratégia muito utilizada nos anos iniciais da educação são as atividades lúdicas, como jogos e passatempos. De acordo com Soares (2003), as atividades lúdicas implicam prazer, divertimento, liberdade e voluntariedade; devem conter um sistema de regras claras e explícitas, além de um local ou instrumento, seja este um espaço físico ou um brinquedo. Segundo Lima (2014), a palavra "lúdica" tem sua origem na língua latina, ludus, que significa jogo, divertimento, entretenimento, brincadeira, $o$ ato de brincar.

Desde os jogos mais antigos, dos quais se tem conhecimento, até os mais modernos, que utilizam excessivamente a tecnologia e têm designs inovadores, o objetivo sempre foi o de proporcionar aos usuários (jogadores) descontração e lazer. Segundo Lima (2014), o lúdico, muitas vezes representado pelo jogo, proporciona uma maior interação social, entre pessoas de diferentes idades, culturas e regiões:

Os jogos lúdicos permitem uma situação educativa cooperativa e interacional, ou seja, quando alguém está jogando está executando regras do jogo e, ao mesmo tempo, desenvolvendo ações de cooperação e interação que estimulam a convivência em grupo (FRIEDMAN, 1998, p. 50).

Aristóteles (384-322 a.C.) tinha a visão de que os jogos eram atividades que preparavam as crianças para a sociedade. Semelhante ao que ocorrera na Grécia antiga, onde os jogos passavam ensinamentos às crianças, no Brasil essa referência surgiu com os indígenas, que ensinavam (e o fazem até hoje) seus costumes por meio da ludicidade: dança, pesca, caça e brincadeiras. Com a falta de letramento dos índios latinos americanos, o conhecimento deveria ser transmitido de alguma maneira que não dependesse da leitura e da escrita, sendo o emprego da ludicidade muito importante na assimilação efetiva dos conhecimentos, especialmente aos jovens. Era por meio da observação dos adultos que as crianças aprendiam os costumes de caçar e pescar e, para eles, esta educação tinha relação direta com o ato de brincar. Embora se esteja adquirindo um conhecimento e desenvolvendo uma habilidade essencial para a sua futura sobrevivência, a criança participa da ação, geralmente, apenas porque nela pode-se divertir (LIMA, 2014). 
Para a prática educacional, as atividades lúdicas conseguem permear entre as principais estruturas para a construção do conhecimento: o desenvolvimento cognitivo, intelectual e social. São capazes de provocar estímulos, explorar os sentidos vitais, operatórios e psicomotores, propiciando o desenvolvimento completo das suas funções cognitivas. Considerando os jogos entre as atividades lúdicas, nota-se que estão presentes até na vida adulta dos indivíduos, o que os tornam utilizáveis em qualquer nível de ensino, não somente para as crianças (SANT'ANNA, 2011).

O processo de aprendizagem assume características como concepções e ideologias, que são típicas de cada indivíduo, segundo suas potencialidades, e de cada cultura em toda sua riqueza e complexidade. É função primordial do professor, como coautor, conduzir esse processo para ações que possibilitem construir os conceitos de forma sequencial, com uma complexidade crescente que propicie a evolução do aluno. A aprendizagem é de extrema relevância, pois permite a apropriação da experiência humana e de habilidades adquiridas ao longo dos anos, além da criação de novas aptidões e funções (ROCHA, 2016).

Para Piaget (1977 apud Cardoso, 2000), o conhecimento se dá a partir da interação com o real, pela assimilação e acomodação de estruturas já existentes, criando condições ao desenvolvimento de novas estruturas. É por meio da interação com o mundo cotidiano que os alunos desenvolvem seus primeiros conhecimentos químicos, uma bagagem de conhecimentos prévios que influenciam no ensino. Um conteúdo de Química ministrado fora deste contexto reduz, significativamente, a aprendizagem dos conteúdos discutidos em sala de aula.

Para garantir um currículo que se harmonize com essa visão mais progressiva de ensino, os PCN ressaltam a importância da articulação entre os conhecimentos de Química e suas aplicações tecnológicas, culturais, ambientais, sociais, políticas e econômicas. Os conteúdos devem contribuir para a promoção de uma cultura científica que permita o exercício da participação social no julgamento, com fundamentos, dos conhecimentos difundidos pelas diversas fontes de informação e na tomada de decisões, seja individualmente ou como membro de um grupo social (MARCONDES, 2018).

Segundo Kishimoto (1996), ao utilizar o jogo como uma metodologia de aprendizagem, devemos apresentar duas funções principais: a lúdica, em o jogo proporciona diversão e prazer, desde que escolhido voluntariamente, mas perdendo tais características quando realizado a contragosto; e a educativa, que propicia o Ensino, enriquecendo e reforçando conhecimentos e saberes já adquiridos. Essas funções devem se harmonizar ao longo do desenvolvimento do jogo, sendo este seu principal objetivo, enquanto estratégia educativa. Quando há desequilíbrio entre essas duas funções, uma se sobressaindo à outra, tem-se duas situações: apenas um jogo, sem aplicação educativa, quando a função lúdica predomina; ou, então, apenas um material didático, caso a função educativa ignore a diversão e a ludicidade, restando apenas ao ensino (SOARES, 2013).

Considerando a importância de se pensar a metodologia em todas as possíveis variações, sejam elas positivas ou negativas no processo de ensino e aprendizagem, a pesquisadora Grando (2000) relacionou as principais vantagens e desvantagens apontadas por alguns estudiosos da aplicação de atividades lúdicas voltadas ao Ensino: Machado (1990); Giménez (1993); Kishimoto (1996); Corbalán 
(1996), que reiteram que tais aspectos devam ser levados em consideração pelo professor que propõe a metodologia em sala de aula, previamente à inserção do jogo.

A literatura demonstra que os jogos educativos permitem revisar conteúdos de forma mais prazerosa. Essa revisão ocorre mais efetiva e rapidamente, devido à forte motivação que o jogo proporciona (RIBEIRO et al., 2017). Segundo Cordeiro (2018), essa motivação proporcionada pelo jogo promove o desenvolvimento de habilidades e familiarização com o conteúdo, além de permitir trabalhar o erro e a dificuldade de forma lúdica. Assim, o jogo de cartas desenvolvido pode auxiliar o professor a verificar possíveis problemas na aprendizagem dos alunos.

Segundo Felício; Soares (2018), as atividades lúdicas em grupo são importantes para desenvolver as habilidades cognitivas dos alunos, como a resolução de problemas, a percepção, a criatividade, o raciocínio rápido, fatores que facilitam tornar dinâmico o processo de ensino e aprendizagem e, dessa forma, vai-se construindo o conhecimento de maneira coletiva e agradável.

Quando a aprendizagem se torna mecânica, sendo necessário apenas decorar conteúdos e formas de resolução de problemas, o aluno provavelmente irá esquecer os assuntos vivenciados logo em seguida, pois seu armazenamento ocorre de forma isolada e momentânea (CAVALCANTE et al., 2018). Essa prévia reflexão foi essencial para a criação da presente proposta, pois nomenclaturas e reações químicas são apresentadas, geralmente, de uma forma mecânica e não desafiadora aos alunos no Ensino Médio.

Os ácidos e as bases constituem um dos conteúdos fundamentais de Química no Ensino Médio relacionando suas aplicações para a indústria e as atividades biológicas. Contudo, apesar destes conceitos estarem presentes na vida cotidiana, não os isenta de problemas e dificuldades relacionados ao seu ensino e a sua aprendizagem (Furió-Más et al., 2007).

Geralmente os conceitos de ácido e bases são apresentados por meio de uma visão cumulativa e linear do conhecimento químico, ignorando os conceitos evolutivos contidos na história da ciência. Furió-Más et al. (2007) argumentam que os estudantes do ensino médio normalmente dissocia a substância ácida com a partícula ou a molécula, não esclarecendo qual é o nível macroscópico e o microscópico, e argumentam que a teoria de Brønsted-Lowry é uma forma melhorada da teoria de Arrhenius. Estas dificuldades conceituais, como a falta de clareza, também é verificada nos livros didáticos (Furió-Más et al., 2005; Souza e Aricó, 2017).

Dessa forma, visando proporcionar uma atividade lúdica que contemple a função de levar aos alunos uma metodologia alternativa, mais prazerosa e diferenciada dos métodos tradicionais de ensino, que possa "competir" com as novas tecnologias, o presente trabalho teve como objetivo o desenvolvimento de um jogo de cartas, denominado "Trinca Química", para revisão de conceitos relacionados a ácidos e bases de Arrhenius, focando nas reações de neutralização entre esses compostos. 


\section{MATERIAIS E MÉTODOS}

O jogo "Trinca Química" foi elaborado a partir da confecção de um conjunto de 52 cartas, as quais são divididas em 3 grupos, identificados na parte superior das cartas como: R1 (verde), R2 (azul) e R3 (laranja). A Figura 1a ilustra algumas dessas cartas. O primeiro grupo (R1) é formado por ácidos e o segundo grupo (R2) é formado por bases. Nesse jogo, as cartas trazem informações como nome, fórmula química ou aplicação do composto químico em questão. O terceiro grupo (R3) é formado pelos sais, gerados a partir da reação química entre um dos ácidos do grupo R1 e uma das bases do grupo R2. A exemplo de R1 e R2, as cartas de R3 também apresentam nome, fórmula química ou aplicação dos referidos sais. A figura $1 \mathrm{~b}$ ilustra o conjunto de cartas para o ácido sulfúrico.

Figura 1 - Representação de algumas cartas para o jogo "Trinca Química"

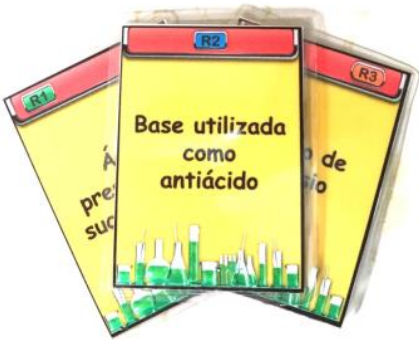

A
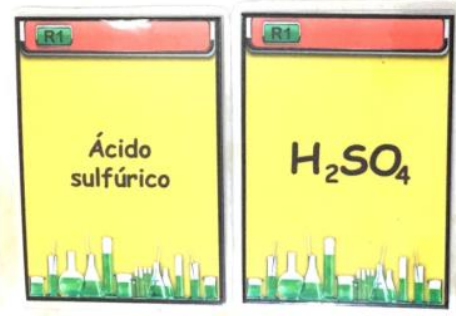

B

Fonte: Autores (2019).

Levando em consideração o tempo curto das aulas de Química no Ensino Médio, sobretudo nas escolas públicas, o jogo foi elaborado apresentando um número relativamente pequeno de compostos, descritos de três diferentes maneiras, a fim de reduzir os tempos das partidas, buscando não ultrapassar o período de uma aula. Assim, o aluno encontra o trio de cartas necessário para concluir o jogo mais rápido, tornando-o mais dinâmico e competitivo. Cumpre lembrar também que o foco central do jogo é o reconhecimento dos compostos envolvidos, por meio de seus nomes, fórmulas e aplicações práticas e não o acerto de coeficientes estequiométricos nas reações de neutralização, que podem ser realizados pelo professor de modo complementar à atividade lúdica. Para aumentar ainda mais a jogabilidade, foi elaborada uma carta "coringa", que substitui qualquer outra carta para formar a reação, sendo ela também interessante para propiciar o desenvolvimento de estratégias de jogo.

A escolha do conteúdo das cartas (as substâncias químicas) foi feita com base na disponibilidade dos materiais didáticos utilizados na escola envolvida e que fazem parte do preparo de aula do professor. As cartas foram criadas empregandose o software CorelDraw $\mathrm{X5}^{\mathrm{Tm}}$, um aplicativo de vetorização, para facilitar a inserção das imagens gráficas que compõem o conjunto de cartas. Após sua elaboração, o arquivo foi convertido em formato Adobe (pdf) para impressão e disponibilização aos interessados. A regra do jogo encontra-se em anexo.

A pesquisa foi aplicada para 15 alunos da Escola Estadual "Adherbal de Paula Ferreira" aos seus 3 o anos do Ensino Médio, na cidade de Itapetininga (SP). Para a atividade lúdica houve a participação de 7 alunos da turma do 3 으 (matutino), e para o método comparativo, 8 alunos da turma do $3^{\circ} \mathrm{A}$ (vespertino), e esta teve a 
revisão através de exercícios em sala e uso do quadro negro. Os mesmos conteúdos didáticos foram ministrados para as duas turmas, só sendo modificada a forma metodológica ao processo de revisão, o "lúdico x exercícios", e em aula futura foi realizada a aplicação de uma lista de exercícios com conteúdos semelhantes para ambas às turmas, ilustrando as comparações quantitativas entre as salas.

Para a obtenção dos dados, durante a aplicação do jogo, foram utilizados registros em diário de campo, gravações em áudio e entrevistas. O objetivo principal da aplicação do jogo foi promover a fixação e auxiliar na compreensão do conteúdo envolvendo reações de neutralização, por meio de uma metodologia lúdica.

A análise dos dados obtidos recebeu uma abordagem qualitativa, segundo as recomendações de Bogdan e Biklen (2000). Para esses autores, o estudo geralmente é conduzido com um pequeno grupo de pessoas para facilitar a investigação por meio de observação. A investigação qualitativa não é feita com o objetivo de responder a questões prévias (específicas ou muito estruturadas), mas, sobretudo, prioriza a compreensão dos comportamentos, a partir da perspectiva dos envolvidos nessa investigação.

As entrevistas que fazem parte da investigação qualitativa têm como característica perguntas poucos estruturadas, sendo que o objetivo principal é que o investigador leve os sujeitos participantes a expressar livremente suas opiniões sobre determinado assunto ou atividade realizada, permitindo uma flexibilidade na condução da mesma.

\section{RESULTADOS E DISCUSSÃO}

Primeiramente, foi perguntado entre os alunos quem teria interesse em participar da atividade proposta, e houve a participação de todos os alunos presentes na sala de aula. É importante que, para se ter prazer em jogar, o sujeito o faça de maneira espontânea, livre de obrigação ou pressão. De acordo com Felício e Soares (2018), a atividade lúdica deve ser acompanhada de um convite àqueles que querem de fato jogar, cabendo ao aluno a decisão sobre sua participação. Quando o jogo se torna obrigatório, tem-se perda da ludicidade, sendo apenas um material didático, argumento este que foi importante para que os alunos optassem pela participação ou não.

Previamente à aplicação da atividade lúdica, houve um momento de revisão dos conteúdos. Foram revisados conceitos envolvendo reações de neutralização, identificação de ácidos e bases, segundo a teoria de Arrhenius, nomenclatura de sais, ácidos e bases, e as aplicações desses compostos químicos na indústria e no cotidiano. A revisão foi explicativa, empregando-se o quadro negro, para que os alunos pudessem iniciar o jogo de maneira mais equilibrada, uma vez que alguns estudantes relataram não se lembrar de maneira satisfatória o conteúdo que seria abordado no jogo de cartas. A revisão foi realizada, em ambas as salas, através da montagem de um fluxograma do conteúdo pedagógico em um período de dez minutos e em seguida o quadro negro foi apagado.

A simplicidade das regras do jogo propiciou uma boa concentração dos alunos. pedagógica lúdica não sejam complexas demais. Devem ser simples e, ao mesmo, 
permitir criar ações livres e estratégias, a fim de que cada aluno possa desenvolver sua própria forma de jogar e sua tática para vencer, propiciando engajamento ao realizar a atividade. Se as regras são complexas, ou seja, se chegarem a comprometer o entendimento do jogo, como consequência ocorrerá demora na compreensão, tornando o jogo pouco dinâmico, podendo até mesmo desmotivar os participantes (FELÍCIO e SOARES, 2018). Por isso, esse cuidado com as regras foi levado em consideração com bastante atenção durante o desenvolvimento deste jogo.

Em cada partida, jogavam dois alunos, que concorriam diretamente entre si para vencer o jogo, seguindo as regras previamente discutidas. Dentre as diversas partidas realizadas, constatou-se uma grande interação entre os alunos e, por sugestão deles próprios, para vencer o adversário, prosseguir na "tabela" e sagrarse campeão, as partidas foram disputadas em um sistema de "melhor de três". Todos os alunos participaram da atividade para montar a "tabela de pontos", e apresentar qual a ordem de classificação final, somando os resultados de todas as partidas, pode-se fazer o resultado para cada aluno e a sua posição em relação aos demais colegas.

Em uma das partidas, foi observada uma grande dificuldade por parte de um dos participantes (Aluno 1), sendo que, em uma de suas primeiras jogadas, ele próprio relatou ter descartado uma carta que seria necessária para suas próximas jogadas e, não conseguindo encontrar a solução, solicitou auxílio a outro aluno que não estava participando daquela partida. Inicialmente, não era intenção do jogo que houvesse interferência de outros participantes que não estivessem na partida, fornecendo ajuda ou dando dicas, porém, sabemos que a cooperação entre os alunos contribui significativamente para a aprendizagem, uma vez que, para ajudar é necessário ter domínio do assunto, além de desenvolver habilidades comunicativas, despertar a percepção das qualidades existentes no outro e ajudar na formação de hábitos sociais (segundo indicações de Brandl Neto e Souza (2016)).

Por esse motivo, passou-se a permitir que os demais colegas pudessem auxiliar os companheiros, estimulando o envolvimento coletivo nos assuntos abordados no jogo. A cooperação foi essencial, pois aos alunos que estavam recebendo ajuda se divertiram sem medo de serem excluídos devido à falta de habilidade. Em um determinado momento do jogo, um dos participantes (Aluno 2) reconheceu sua dificuldade em jogar por não dominar os conceitos que estavam sendo revisados durante o jogo. Diante disso, ele sugeriu que a vez de jogar fosse passada a outro participante: "Quero trocar, não quero mais jogar [...] eu vou trocar com ela (Aluno 2)".

Imediatamente, os demais alunos que estavam observando o jogo motivaram o Aluno 2 a continuar jogando, dizendo que ele iria conseguir e que, se precisasse, iriam ajudá-lo. Segundo Brandl Neto e Souza (2016), tal comportamento indica que a cooperação entre os alunos é benéfica para ambos os lados, uma vez que o aluno que se viu desmotivado e demonstrou querer encerrar o jogo por acreditar que não seria capaz, não foi excluído da atividade e, recebendo ajuda dos demais colegas e incentivo, conseguiu concluir o jogo, tendo inclusive vencido uma das partidas em que ele participou. Ele afirmou: "[...] agora eu sei como jogar! Estou mais confiante e sei que posso tentar mais vezes. (Aluno 2 )". 
Para Huizinga (1971), um jogo bem concebido socializa e estimula o trabalho em equipe e a cooperação, desperta a criatividade, a participação e a competição sadia. Quando se propõe um jogo, existe naturalmente uma competição entre os alunos e a vontade de ganhar faz com que todos se esforcem para relembrar os conceitos necessários à vitória; e isso serve como motivador para realizar a atividade. A cooperação entre os alunos não prejudica o espírito competitivo da atividade lúdica, pelo contrário, estimula uma competição saudável em que os alunos querem vencer, mas ao mesmo tempo se solidarizam com as dificuldades dos colegas. Tal cenário foi observado na aplicação do jogo de cartas em sala de aula, demonstrando claramente a eficiente metodologia para uma formação cidadã, como incentivada junto ao PCN.

Conforme os alunos jogavam, foi possível observar uma melhora significativa em relação ao envolvimento deles com os conteúdos relacionados: "[...] mas você ainda tem chance, pode pegar $\mathrm{HCl}$ ou ácido presente no suco gástrico (Aluna 3)" e "Fica com essa aqui, o $\mathrm{HNO}_{3}$ é o ácido nítrico (Aluna 4)". Os alunos passavam a interpretar melhor as cartas e a criar estratégias para vencer a partida, com isso, sempre verificavam as relações da nomenclatura e a reatividade entre as moléculas.

Com o tempo, as partidas foram se tornando mais dinâmicas e competitivas. Os alunos expressavam emoções, dificilmente observadas em sala de aula, durante as aulas tradicionais: "Ai que raiva! Eu perdi a carta que podia dar certo (Aluno 1)", "Agora eu consegui! ufa!", "Não acredito que eu venci! (Aluna 6)". Conforme próprio relatado em entrevista pela professora da disciplina de Química os alunos apresentaram uma espontaneidade em informar suas dificuldades em aulas futuras, situação esta até então pouco usual em suas aulas: "Um aluno veio até mim e disse: professora, agora você sabe qual é o meu maior problema aqui na Química, é decorar estes nomes, até sei o que é cloro ou sulfato, mas a montagem é que fico meio perdido (Professora)".

Cumpre lembrar que a jogabilidade depende dos conhecimentos prévios dos alunos e, evidentemente, quanto melhor for o domínio dos conhecimentos propostos na atividade lúdica, mais fácil será jogar, obter melhores resultados e chegar à vitória na partida disputada. Contudo, apesar de envolver o conhecimento químico para consolidar a função educativa do jogo, que é revisar conceitos de interesse, trata-se, ao mesmo tempo, de um jogo de sorte, no qual os participantes podem desenvolver estratégias e usar seus próprios conhecimentos. Dessa forma, mesmo que haja completo domínio do conteúdo, é preciso um pouco de sorte para completar o jogo, uma vez que as cartas são embaralhadas aleatoriamente, não havendo opção de escolha, o que fornece ainda mais equilíbrio e disputa nas partidas, fato que estimula o envolvimento de alunos que não possuem tanta afinidade pela disciplina de Química, mas sim auxiliam na revisão dos conceitos.

A percepção dos alunos sobre jogo também mudou conforme se envolviam nas partidas. Por depender de sorte para se obter a carta necessária para fechar as trincas, em determinado momento os alunos passavam a desenvolver estratégias variadas. A Aluna 3, por exemplo, quando foi convidada a jogar outra partida, disse: "[...] agora não, eu tô pensando! É que tem uma estratégia, porque não pode ficar segurando a carta [...] vou só olhar (Aluna 3)". Essa atitude só foi observada quando os alunos haviam assimilado de fato os conhecimentos abordados nas cartas e passaram a conseguir identificar e relacionar os compostos com maior 
facilidade, caracterizando didaticamente como melhora na revisão dos conceitos químicos sobre a nomenclatura de ácidos e bases.

Dentre as vantagens em se aplicar uma atividade lúdica, como as apontadas por Grando (2000), observou-se que a fixação dos conceitos foi realizada de forma motivadora para os alunos, uma vez que os mesmos estavam empolgados em participar da atividade e concentrados, mesmo quando não era sua vez de jogar.

A assimilação dos conceitos durante a aula, segundo os alunos, é difícil pois, como na concepção deles os conteúdos devem ser decorados somente para as provas, eles acabam não se preocupando em fixá-los na memória por muito tempo. No caso da Trinca Química, houve desenvolvimento de estratégias, tornando o jogo mais desafiador, exigindo do aluno raciocínio, criatividade, e senso crítico; o uso de perguntas do cotidiano relacionadas com as cartas propostas permitiu relacionar fórmulas e aplicações de substâncias químicas, familiarizando os alunos com diversas formas de linguagem. Também houve socialização do conhecimento entre os alunos, bem como participação ativa e cooperativa de todos na construção do conhecimento, envolvendo-os em uma competição sadia.

O reforço de habilidades necessárias, mesmo com os alunos em diferentes níveis de conhecimento, possibilitou verificar que houve participação ativa de todos, sendo que o mais significativo foi que permitiu ao professor identificar as principais dificuldades de aprendizagem e verificar a importância do envolvimento cooperativo dos alunos para o processo de ensino e aprendizagem. Assim, o desenvolvimento e aplicação desse jogo representou uma excelente alternativa metodológica para o ensino de Química, com possibilidades de ser adaptado a outros assuntos dentro da própria Química e também para outras disciplinas. A observação dos diários de campo demonstrou que houve o desenvolvimento pedagógico dos alunos durante o jogo e, também pela vontade de participar, o comportamento entre eles no momento da atividade foi bem mais proativo do que o observado durante as aulas tradicionais.

Ao final da aplicação, os alunos relataram que a atividade foi muito interessante para revisar a matéria. As descrições da gravação também corroboram as declarações feitas ao final da atividade: " [...] não é legal ficar fazendo só exercícios, assim é mais empolgante, acho que revisei da mesma forma, mas sem cansar" (Aluna 3)". Durante a entrevista final, o Aluno 4 declarou não lembrar nada daquela matéria, e disse: " [...] eu não guardo nada disso aqui na memória. Os escritos eu nem sei mas, se eu jogar várias vezes, vou lembrar, até já sei vários nomes agora, acho que assim me ajudou a memorizar estes nomes e suas moléculas" (Aluna 4)".

Alguns assuntos de Química requerem memorização, como nomes de compostos, fórmulas químicas e suas aplicações, bem como certas fórmulas conceituais inerentes ao próprio currículo da disciplina. No entanto, é importante destacar que os PCN não incentivam restringir o Ensino de Química, pragmaticamente, à memorização de leis e fórmulas. Para Nardin (2008), com o estímulo correto, o jogo, pode ser uma ferramenta útil para facilitar os estudos, favorecer o desenvolvimento do intelecto e até mesmo a memorização de certos conceitos, como observado na análise dos resultados.

Os alunos afirmaram terem se sentido desafiados inicialmente pelo jogo e achavam que se tratava de um jogo com alto nível de dificuldade. A seguir, alguns relatos da atividade pelos alunos: "No começo foi difícil, né? (Aluno 1)"; "É! Foi só 
até pegar o jeito (Aluno 5)"; "Com o tempo foi ficando mais fácil (Aluna 6)"; "Ganhei todas! Eu mereço um 10 em Química! (Aluno 2)" e "Interessante! Interessante! Eu gostei muito! (Aluna 7)".

Além das observações e relatos dos alunos, a professora que os acompanhou na aplicação do jogo demonstrou surpresa ao observar que um de seus alunos estava participando da atividade e se esforçando para entender os conceitos químicos presentes no jogo, uma vez que se tratava de um acadêmico que pouco participava das aulas, nunca perguntava nada a respeito dos conteúdos abordados e nem demonstrava interesse pela disciplina. Por isso, foi surpreendente para a professora de Química, a disposição desse aluno de procurar acertar as disposições das cartas e envolver-se nas discussões com os colegas.

A professora fez um relato após a aplicação da atividade referente a este episódio: "[...] esse aluno era muito pouco participativo em minhas aulas, o que refletia diretamente em seu rendimento nas avaliações. Me surpreendi, mesmo! Além dele ficar mais atento em minhas aulas agora, interage bastante com a disciplina. (Professora)".

Em decorrência da voluntariedade do aluno, que assumiu o compromisso de participar, as observações demonstraram que o jogo também propiciou uma maior proximidade nas relações entre os alunos e deles com a professora. Segundo Felício e Soares (2018), o professor, ao explorar a motivação dos alunos, enriquece sua atuação didática e consegue perceber e valorizar o que o aluno já conhece.

Um estudo comparativo entre duas turmas em que a professora ministrou o mesmo conteúdo na escola, com a diferença que a revisão para uma sala foi executada através da resolução e discussão de exercícios em sala e a outra com a aplicação da atividade lúdica proposta, demonstrou uma diferença no resultado final da média das avaliações das turmas. A média da avaliação para a sala em que ocorreu a revisão através do jogo de cartas foi de 7,9 , bem superior a média da outra sala em que a revisão foi feita por uma lista de exercícios, obtendo a média de 5,2. Cabe lembrar que geralmente, as notas das médias entre as duas salas sempre se mantiveram muito próximas, com diferenças na casa de 0,5 , ilustrando que a aplicação desta atividade lúdica atingiu seu objetivo para a revisão de conceitos de nomenclatura para ácidos e bases, e como também na melhora das interações pessoais na sala de aula, tornando um ambiente escolar mais motivador e interessante aos alunos.

\section{COSIDERAÇÕES FINAIS}

Considerando todas as observações realizadas, podemos concluir que o jogo atingiu de forma plena os objetivos que se pretendiam alcançar com sua aplicação. Além de envolver os alunos do Ensino Médio em uma metodologia lúdica alternativa de aprendizagem, que demonstrou estimular o envolvimento dos estudantes para os conteúdos de Química abordados, o desenvolvimento do jogo também contribuiu para a formação inicial de estudantes de licenciatura em Química e para a formação continuada da professora da disciplina.

O emprego de atividades lúdicas tem sido amplamente debatido nas revistas da área de Ensino de Química e tem se demonstrado um caminho bastante eficaz para melhorar o processo de ensino e aprendizagem de conceitos químicos de uma maneira mais prazerosa para os alunos. Além disso, as atividades lúdicas também 
são importantes motivadores para a integração entre os alunos, para a melhora na relação professor-aluno. Interpretamos que a combinação do ensino tradicional com aplicações de metodologias alternativas lúdicas, como a proposta neste artigo, pode constituir um fator decisivo para melhorar o interesse dos estudantes pela Química. 


\title{
THE IMPORTANCE OF EMPLOYMENT A CARD GAME FOR THE REVISION TO NOMENCLATURE OF ACIDS AND BASES
}

\begin{abstract}
Ludic activities have been the object of study in a number of works in literature related to the Teaching of Chemistry. The present work has been inserted in that context, by the elaboration and application of a playful pedagogical material, aiming to review concepts of Inorganic Chemistry, more precisely involving applications, nomenclature and concepts related to Arrhenius acids and bases. To this end, a game of cards called "Chemical Crack" was elaborated with a deck of 52 cards and applied to a High School classroom from a public State School. The results were quite satisfactory and the acceptance of the methodology by the students was very significant, having been verified the importance and contribution of the game to the stimulus to learning, reviewing and consolidating concepts explored in the classroom. Furthermore, the game allowed to evaluate possible learning difficulties, as well as ways to overcome them. The proposal was also very well received by the teacher of Chemistry, who also reported an enhancement in the relationship with the students after the application of this methodology in classroom.
\end{abstract}

KEYWORDS: Ludic activities. Chemical education. Games. 


\section{REFERÊNCIAS}

BOGDAN, R.; BIKLEN, S. Investigação qualitativa em educação. Porto: Porto Editora, 2000.

BRANDL NETO, I.; SOUZA, S. A. Jogos e Brincadeiras: O Lúdico e a Cooperação nas Aulas de Educação Física. Caderno PDE Governo do Estado do Paraná, Volume 1, 2016.

BRASIL. PCN+ Ciências da Natureza, Matemática e suas Tecnologias. Portal do Ministério público, 2006.

BRASIL. Resolução CEB no 3, de 26 de junho de 1998: Institui as Diretrizes Curriculares Nacionais para o Ensino Médio. Portal do Ministério público, 1998.

CARDOSO, S. P.; COLINVAUX, D. Explorando a motivação para estudar química. Química Nova, v. 23, n. 2, p. 401-404, 2000.

CAVALCANTE, M. P.; OLIVEIRA, A. L.; OLIVEIRA, J. C. P.; NASSER, M. J. S. O Jogo Educativo como Recurso interdisciplinar no Ensino de Química. Química Nova na Escola, v. 40, n. 2, p. 289-96, 2018.

CORDEIRO, D. O.; SILVA, J. E.; SILVA JÚNIOR, C. N.; OLIVEIRA, Ó. A. Pistas Orgânicas: um jogo para o processo de ensino e aprendizagem da química. Química Nova na Escola, v. 40, n. 1, p. 25-32, 2018.

CUNHA, M. B. Jogos no Ensino de Química: Considerações Teóricas para sua Utilização em Sala de Aula. Química Nova na Escola, v. 34, n. 2, p. 92-98, 2012.

DROUET, R. C. R. Distúrbios de aprendizagem. São Paulo: Ática, 1995.

FELÍCIO, C. M.; SOARES, M. H. F. B. Da Intencionalidade à Responsabilidade Lúdica: Novos Termos para uma Reflexão Sobre o Uso de Jogos no Ensino de Química. Química Nova na Escola, v. 40, n. 3, p. 160-168, 2018.

FRIEDMANN, A. Brincar, crescer e aprender: o resgate do jogo infantil. São Paulo: Moderna, 1998. 
FURIÓ-MÁS, C.; CALATAYUD, M. L.; BÁRCENAS, S. L. Surveying students' conceptual and procedural knowledge of acid-base behavior of substances. Journal of Chemical Education, v. 84, n. 10, p. 1717-1724, 2007.

GARCEZ, E. S. C. O lúdico em Ensino de Química: um estudo do estado da arte. 2014. Dissertação (Pós-Graduação em Educação em Ciências e Matemática) Universidade Federal de Goiás. Goiânia, 2014.

GIORDAN, M. O papel da Experimentação no Ensino de Ciências. Química Nova na Escola, v. 10, n. 2, p. 43-49, 1999.

GRANDO, R. C. O Conhecimento Matemático e o Uso de Jogos na sala de aula. 2000. Tese (Doutorado da Faculdade de Educação) - UNICAMP. Campinas, 2000.

HUIZINGA, Johan. Homo Ludens: O Jogo Como Elemento da Cultura. 5. ed. São Paulo: Editora Perspectiva, 1971.

KISHIMOTO. T. M. Jogo, Brinquedo, Brincadeira e a Educação. São Paulo: Cortez Editora, 1996.

LIMA, A. J. A. O lúdico em clássicos da filosofia: Uma análise em Platão, Aristóteles e Rousseau. 2014. Dissertação (Pós-Graduação em Educação) Universidade Federal do Maranhão. São Luís, 2014.

MARCONDES, M. E. R. As ciências da natureza nas 1a e 2a versões da Base Nacional Comum Curricular. Estudos Avançados, v. 94, p. 269-284, 2018.

MIRANDA, M. I. Crianças com problemas de aprendizagem na alfabetização: contribuições da teoria piagetiana. Araraquara: JM Editora, 2000.

MORADILLO, H. S.; MESSEDER, E. F. O Lúdico no Ensino de Química: Considerações a partir da Psicologia Histórico-Cultural. Química Nova na Escola, v. 38, n. 4 , p. $360-368,2016$.

NARDIN, I. C. B. Brincando aprende-se química. Dia a dia educação: Secretaria do Paraná, 2008.

RIBEIRO, M. E. N. P.; OLIVEIRA, J. J. S.; MORAIS, R. O.; MEDEIROS, U. K. L. Criação do Jogo "Um Passeio na Indústria de Laticínios" visando promover a Educação Ambiental no Curso Técnico de Alimentos. Química Nova na Escola, v. 39, n. 2, p. 
ROCHA, J. S.; VASCONCELOS, T. C. Dificuldades de aprendizagem no ensino de química: Algumas reflexões. In: XVIII Encontro Nacional de Ensino de Química (XVIII ENEQ), 2016, Florianópolis: Universidade Federal de Santa Catarina - SC, 2016.

SÁ, H. C. A.; SILVA, R. R. Contextualização e Interdisciplinaridade: Concepções de professores no ensino de gases. In. XIV Encontro Nacional de Ensino de Química (XIV ENEQ), 2008, Curitiba: Universidade Federal do Paraná - PR, 2008.

SANTANA, E. M. A influência de atividades lúdicas na aprendizagem de conceitos químicos. 2008. Dissertação (Pós-Graduação Interunidades em Ensino de Ciências) - Universidade de São Paulo. São Paulo, 2008.

SOARES, M. H. F. B. Jogos e Atividade Lúdicas no Ensino de Química: Teoria e Métodos. In: XIV Encontro Nacional de Ensino de Química (XIV ENEQ),2013, Goiânia: Universidade Federal de Goiás - GO, 2013.

SOARES, M. H. F. B.; OKUMURA, F.; CAVALHEIRO, É. T. G. Proposta de um jogo didático para ensinar o conceito de equilíbrio químico. Química Nova na Escola, v. 18, n. 2, p. 13-17, 2003.

SOUZA, F. M.; ARICÓ, E. M. Mapa cronológico da evolução das definições ácidobase: um potencial material de apoio didático para contextualização histórica no ensino de química. Educación Quimica, v. 28, p. 2-10, 2017.

\section{ANEXOS}

\section{ANEXO 01}

As regras do jogo são relativamente simples:

- O jogo deve iniciar com, no mínimo, 2 participantes;

- Todas as cartas são previamente embaralhadas e colocadas com a face voltada para baixo, não podendo ser vistas pelos jogadores;

- Cada jogador (aluno) retira 3 cartas do topo do deck para o início da partida;

- Lembrando que o objetivo do jogo é formar os trios que completam as reações de neutralização, portanto, em cada conjunto deve haver uma carta de cada grupo (R1, R2 e R3) que corretamente formem uma reação química;

- A cada rodada o jogador deve "comprar" uma carta e, em seguida, fazer o descarte de uma carta com a frente voltada para cima; 
- A carta descartada deve formar um novo monte, porém, este com a face voltada para cima, visível a todos os jogadores;

- A carta a ser comprada pode ser do monte fechado ou do descarte dos outros jogadores, caso seja interessante e, neste caso, deve-se comprar apenas a última carta de descarte, ou seja, a carta que estiver em cima;

- O jogador pode "montar" a neutralização com as cartas quaisquer do ácido (R1) e da base (R2), desde que a carta do grupo R3 seja, de fato, correspondente ao sal, produto da reação química entre o ácido da carta R1 com a base da carta R2;

- Formada uma reação o aluno deve comprar três novas cartas para dar continuidade ao jogo;

- O jogo termina quando algum dos jogadores formar três conjuntos de neutralização de forma correta.

Recebido: 01 out. 2019

Aprovado: 29 mar. 2020.

DOI: $10.3895 /$ rbect.v13n3.10906

Como citar: FILHO, E. B.; CAVAGIS, A. D. M.; CESAR, R. M.; BENEDETTI, L. P. S. A importância do

emprego de um jogo de cartas para a revisão da nomenclatura de ácidos e bases. Revista Brasileira de

Ensino de Ciência e Tecnologia, Ponta Grossa, v.13, n. 3, p. 264-280, set./dez. 2020. Disponível em:

<https://periodicos.utfpr.edu.br/rbect/article/view/10906>. Acesso em: XXX.

Correspondência: Edemar Benedetti Filho - edemar@ufscar.br

Direito autoral: Este artigo está licenciado sob os termos da Licença Creative Commons-Atribuição 4.0

Internacional. 